\title{
ION AND FAST NEUTRAL BOMBARDMENT OF SURFACES IN CONTROLLED FUSION DEVICES
}

\section{PLASMA PHYSICS LABORATORY}

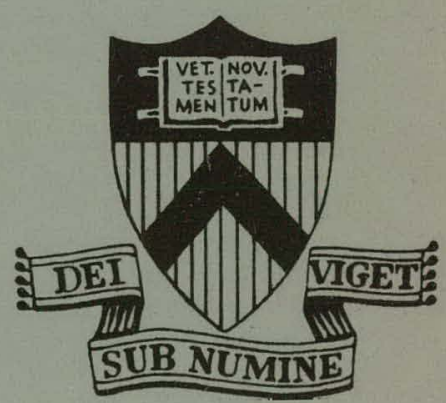

\section{PRINCETON UNIVERSITY PRINCETON, NEW JERSEY}

This work was supported by U. S. Atomic Energy Commission Contract AT (11-1)-3073. Reproduction, translation, publication, use, and disposal, in whole or in part, by or for the United States Covernment is permitted. 


\section{DISCLAIMER}

This report was prepared as an account of work sponsored by an agency of the United States Government. Neither the United States Government nor any agency Thereof, nor any of their employees, makes any warranty, express or implied, or assumes any legal liability or responsibility for the accuracy, completeness, or usefulness of any information, apparatus, product, or process disclosed, or represents that its use would not infringe privately owned rights. Reference herein to any specific commercial product, process, or service by trade name, trademark, manufacturer, or otherwise does not necessarily constitute or imply its endorsement, recommendation, or favoring by the United States Government or any agency thereof. The views and opinions of authors expressed herein do not necessarily state or reflect those of the United States Government or any agency thereof. 


\section{DISCLAIMER}

Portions of this document may be illegible in electronic image products. Images are produced from the best available original document. 
Ion and Fast Neutral Bombardment of Surfaces in Controlled Fusion Devices

Harolyn K. Perkins

Program of Fusion Reactor Technology

Department of Chemical Engineering

Princeton University

Princeton, New Jersey 08540

\section{ABSTRACT}

The erosion of ferrous- and nickel-alloy walls in fusion reactors from impinging, energetic D-, T-, He-, and $\mathrm{Ar}-$ ions and neutrals is discussed. The two major mechanisms of erosion are sputtering and blistering. Pertinent data are reviewed to obtain esti-. mated or experimental sputtering yields in the energy range $100 \mathrm{eV}$ to $10 \mathrm{keV}$. The sputtering coefficients for $\mathrm{Ar}, \mathrm{He}$; and $\mathrm{T}$ are roughly $10^{2}, 10$, and 1.5 times the value for $D$ (at the same energy). Erosion from blistering is unimportant for $\mathrm{Ar}$, unexamined for $\mathrm{D}$ or $\mathrm{T}$, and probably comparable to sputtering for $\sim 10 \mathrm{keV}$ He.






\section{INTRODUCTION}

Ion and fast neutral bombardment (hydrogen isotopes, helium, impurities) of surfaces in controlled fusion devices affect the influx of cold particles to the plasma, the lifetime of reactor walls, and the tritium hold up and recovery route. Erosion due to the physical and chemical sputtering or blistering and embrittlement resulting from gas hold up may.preclude reasonable wall lifetimes. Data on the sputtering coefficients for all plasma particles over a wide energy range are not available nor are hard numbers available to predict the identity; number, and energy distribution of the bombarding particles.

Erosion due to physical sputtering is strongly dependent on the mass and atomic number of both the bombarding species and the wall atoms as well as the energy and flux of the incoming energetic ions and neutrals. The implantation of energetic gaseous ions and neutrals produces drastic changes in the surface layers of metals: a large number of metal lattice vacancies and interstitials; a gas atom concentration that may equal the metal atom concentration; and electron excitation and thermal heating. The majority of these implanted gas atoms will be re-emitted at the bombarded surface for the metals that we consider, such as ferrous- and nickel-alloys, at temperatures around $500^{\circ}$. C. Under certain unpredictable conditions some of this re-emission may result from the bursting of gas-filled bubbles that form in the surface layer by a coalescence of gas trapped at vacancies. This phenomenon, which is referred to as blistering, has recently been observed 
for He bombarding stainless steel ${ }^{1}$ and nickel. ${ }^{2}$ Some of the implanted hydrogen may migrate into the bulk of the metal wall and either become trapped at energetically favored sites, form a dilute solution in the metal, or be emitted at the unbombarded side. Too high a concentration of hydrogen in the bulk of the metal is undesirable because of degradation of mechanical strength by hydrogen embrittlement (especially important on cool down) and the desire to keep the tritium inventory as low as possible. The aim of Sec. II is to indicate the gross characteristics of the bombarding particles impinging on the first wall. In Sec. III we present pertinent sputtering data, make necessary extrapolations to obtain estimates for needed sputtering coefficients and then calculate the wall erosion resulting from possible bombardment situations. The problem of blistering is addressed in Sec. IV. Finally in Sec. V we summarize the implications of our analysis to both reactors and experimental plasma devices and the areas where more experiments are needed.

\section{THE BOMBARDING SPECIES}

A D-T reactor plasma'such as that proposed by the Princeton Reactor Studies Group (PR SG) contains $\mathrm{D}^{+}, \mathrm{T}^{+}, \mathrm{Ar}^{18+}$, and impurities, e.g., Fe $26+$, with an average energy of about $15 \mathrm{keV}$ and $\mathrm{He}^{2+}$ ions with energies from $3.5 \mathrm{MeV}$ down. The average $\mathrm{He}^{2+}$ energy in this burning plasma is expected to be in the range 10-50 kev. ${ }^{3}$ our reference to $\sim 10 \mathrm{keV}$ ions is meant to include these 10-50 keV He $\mathrm{He}^{2+}$ ions. The question of how many $\sim 10 \mathrm{keV}$ particles reach the first wall is difficult to answer and 
* model-dependent. (The lowest estimate is essentially none. ${ }^{3}$ ) Bombardment of the first wall by $\geq 10 \mathrm{keV}$ ions may result from plasma instabilities. Bombardment by $\sim 10 \mathrm{keV}$ neutrals, primarily $\mathrm{D}$ and $\mathrm{T}$, can result from charge exchange if. cold neutrals or partially-stripped ions enter the burning plasma. (The probability of $\mathrm{He}^{2+}$ acquiring two electrons via charge exchange is . thought to be low so that bombardment by $\gtrsim 10 \mathrm{kev-He}$ neutrals * may be negligible.)

Possible sources of neutrals or partially-stripped ions entering a burning plasma are re-fueling by injection of neutral pellets or neutral beams as well as neutrals coming from the first wall or divertor region. A proposed model ${ }^{4}$ for the divertor and scrape-off region keeps unwanted neutrals from the burning plasma; however, it is probably overly optimistic to assume that no neutrals will get to. its edge. In this model ${ }^{4}$ the first wall will also be bombarded by ions and neutrals having energies characteristic of the scrape-off region $(\sim 5 \mathrm{eV})$ and the transition region between the burning plasma and scrape-off region ( $5 \mathrm{eV}$ to $10 \mathrm{keV})$.

The damage to the first wall from bombardment is assumed to be directly proportional to the flux, for a given energy and identity of bombarding particles. (It is essentially independent of the charge on the particle so that damage from ions and neutrals of the same species and energy will be similar.) since uncertainties exist in the fluxes, energies, and identity of the particles that will bombard the various regions of the first wall, we consider the damage associated with a wide span of energies. 
Using existing experimental data we will estimate erosion rates for assumed fluxes to indicate required limits on these fluxes commensurate. with reasonable first wall lifetimes.

\section{SPUTTERING}

When energetic particles bombard target materials with energy above a threshold value ( $10 \mathrm{eV})$, they penetrate the surface and initiate a transfer of energy to target atoms so that some of them are ejected from the surface. This process is referred to as sputtering. The number of ejected target atoms per incident particle is the sputtering coefficient. The incident particles in most sputtering experiments have been ions, however, the sputtering yield is assumed to be independent of the charge on the bombarding particle.

A qualitative picture of sputtering from a random target follows. An impinging particle undergoes a..series of collisions in the target; atoms that recoil with enough energy undergo secondary collisions, thereby creating another generation of recoiling atoms. The incident particles and energetic recoil atoms have the possibility of getting back-scattered out of the target surface with an appreciable fraction of their initial energy. Since the second generation of scattered target atoms have much lower recoil energy and consequently shorter range, only those located originally within a few atomic layers of the surface will retain sufficient enèrgy to overcome the surface binding force and be ejected. The majority of the sputtered atoms result from these 
secondary collisions in the surface region. Hence the sputtering yield depends primarily on: (1) the energy deposited in the surface region of the target by both the bombarding particle and energetic recoil atoms and (2) the surface binding energy.

The surface binding energy depends on surface impurities, absorbed or adsorbed gas, and the crystallographic plane or planes at the surface. Thus sputtering yields are dependent on the existing surface conditions. The temperature of polycrystalline targets is not likely to be a significant factor as long as its well below the melting point. In the case of reactive bombarding species, such as hydrogen, chemical forces may play a significant role in the sputtering process and molecules like $\mathrm{NiH}$ could be ejected.

The maximum energy that can be transferred in a two-body collision is limited by conservation of momentum and energy to $4 m_{1} m_{2} /\left(m_{1}+m_{2}\right)^{2} E_{1}$, where $m_{1}$ and $E_{1}$ are the mass and energy of the incident particle in the reference frame where the second particle of mass $m_{2}$ is at rest. When $m_{1}=m_{2}$ all of the energy can be transferred. The transferred energy decreases as the mass ratio $\mathrm{m}_{1} / \mathrm{m}_{2}$ departs from one; this is reflected in similar decreases in sputtering yields; however, this simplified model does not quantitatively give the mass dependence of the sputtering yields:

The sputtering yield exhibits a maximum when the angle of incidence is about $60^{\circ}-70^{\circ}$ from normal. 5 Most sputtering data are for normal incidence; incidence at $\sim 60^{\circ}$ from normal could increase the yield by an order of magnitude. 
A representative curve showing the dependence of the sputtering coefficient $S(E)$ on the energy $E$ is shown in Fig. 1 . The rather broad maximum which occurs around $1 \mathrm{keV}$ to $10 \mathrm{keV}$ reflects the energy region where the increasing penetration depth of the bombarding particle results in a smaller fraction of its total energy being deposited in the surface region.

\section{Available Data}

A number of review articles on sputtering contain collections of existing data and details of various theoretical models. ${ }^{5-11}$ No pertinent sputtering data found for the PRSG proposed first wall alloy, Nimonic P.E.16 containing primarily 44\% $\mathrm{Ni}, 17 \% \mathrm{Cr}, 1 \% \mathrm{Ti}$, $3 \% \mathrm{Mo}$, and $35 \% \mathrm{Fe} ;$ however, its sputtering coefficient is not likely to differ appreciably from that of $\mathrm{Fe}$ and Ni. (The available sputtering coefficients for these two metals are within a factor of two.) Figures 2-8 are plots of the more pertinent sputtering data to the first wall erosion of ferrous- or nickelbased alloys.

Guseva's data ${ }^{12}$ on the sputtering yields for stainless steel bombarded by 5 - $30 \mathrm{keV} \mathrm{D}_{:}^{+}$(Fig. 2) show that $S$ is essentially the same at 5 and $10 \mathrm{keV}$ and decreases at higher energies. The most extensive collection of sputtering data comes from Wehner and co-workers., ${ }^{13-16}$ who measured the sputtering yields for the inert gases over the energy range 0 to $600 \mathrm{eV}$ and for $\mathrm{H}_{2}^{+}$ and $\mathrm{H}_{3}^{+}$with an energy of $7 \mathrm{keV}$ on many metal targets. Their data for $\mathrm{He}^{13,14}$ and $\mathrm{Ar}^{13,15}$ bombardment of $\mathrm{Fe}, \mathrm{Cr}$, and $\mathrm{Ni}$ are plotted in Figs. 3 and 4: Similar values for Ar bombardment have 
been reported by weijsenfield et al. 17 No data were found for hydrogen in this low energy range; however, later in this section we will scale some data on silver to estimate a value for $700 \mathrm{eV}$. Figures 5 and 6 are plots of the sputtering yield of $300 \mathrm{eV} \mathrm{He}^{+}, 14$ and $7 \mathrm{keV} \mathrm{H}_{2}^{+}, 16$ as a function of the atomic number of the target material. A strong periodic dependence of the yield exists in metals for all bombarding ions with maxima occurring at $\mathrm{Cu}$, Ag, and $A u$, which is correlated to the filling of the $3 d, 4 d$, and $5 d$ shell. This consistency gives us a certain amount of confidence in scaling the rather extensive sputtering data of Gronlund and Moore ${ }^{18}$ on silver shown in Figs. 7 and 8 to obtain estimated sputtering yields on iron and nickel.

The sputtering yield for molecular ions such as $7 \mathrm{keV} \mathrm{\textrm {H } _ { 2 } ^ { + }}$ in Fig. 7 is used to calculate the yield for $3.5 \mathrm{keV} \mathrm{H}^{+}$by assuming that the energy is equally divided between the $H$ nuclei which then sputter independently. Similarly the data for $2 \mathrm{keV}_{3}^{+}$on silver in Fig. 8 can be used to obtain sputtering yields for $700 \mathrm{eV} \mathrm{H}^{+}$on silver. This implies that the sputtering yield for $\mathrm{H}$ and $\mathrm{D}$ is roughly constant over the energy range $1 \mathrm{keV}$ to $12 \mathrm{keV}$ with the value of $D$ falling off more at the higher energies than that for $H$. Also the value for $D$ is more than twice the value for $\mathrm{H}$.

A summary of experimental sputtering yields for $\mathrm{H}^{+}, \mathrm{D}^{+}, \mathrm{He}^{+}$, $\mathrm{Ar}^{+}, \mathrm{Fe}^{+}, \mathrm{Ni}^{+}$, and $\mathrm{Cr}^{+}$bombardment of $\mathrm{Fe}, \mathrm{Ni}, \mathrm{Cr}$, and stainless steel targets is given in Table I. Except for $\mathrm{Ar}^{+}$on Fe we can see that the existing data fail to cover a wide spectrum of energies. Sputtering data for $\mathrm{Fe}, \mathrm{Cr}$, and $\mathrm{Ni}$ bombarding ions are 
of interest since sputtered wall atoms may become energized in the plasma and return to the wall to produce additional sputtering. Assuming that the data on silver and iron scale as in Figs. 5-8 we estimate sputtering yields on iron- nickel-chromium alloys in the energy range $1 \mathrm{keV}$ to $10 \mathrm{keV}$ to be 0.03 for $\mathrm{D}, 0.04$ for $\mathrm{T}$, 0.3 for He, and 2.0 for Ar. These values are expected to be good to better than an order of magnitude and, in fact, the value obtained this way falls within a factor of two of the experimental data in Fig. 2. for $\mathrm{D}$ on stainless steel. We feel less certain about scaling and extrapolating the sputtering data for $\mathrm{H}$ to estimate the yields for $\mathrm{D}$ and $\mathrm{T}$ at energies below I $\mathrm{kev}$; however; we assume that they fall off linearly below $1 \mathrm{keV}$.

\section{Wall Erosion}

For a twenty year lifetime the wall erosion rates cannot appreciably exceed $10^{-2} \mathrm{~cm} /$ year. The yearly erosion rate from. sputtering by particle $i$ with energy $\mathrm{E}$ is

$$
\begin{aligned}
& T_{i}(E)=C S_{i}(E) J_{i}(E)=3.8 \times 10^{-16} \frac{\mathrm{cm} \mathrm{sec}}{\text { year atom }} S_{i}(E) J_{i}(E) \\
& C=\left(3.16 \times 10^{7} \frac{\mathrm{sec}}{\text { year }}\right) n^{-1} \\
& n \cong 8.4 \times 10^{22} \frac{\text { atoms }}{C C}
\end{aligned}
$$

Here $\mathrm{T}_{i}$ is the thickness that is eroded in $\mathrm{cm} /$ year; $C$ is a constant that varies with the atomic density of the wall, $n$, as shown and is assigned a value that is typical of ferrous- and nickel-alloys, $S_{i}(E)$ is the sputtering coefficient of projectile $i$ with energy $E$ in atoms/ion, and $J_{i}(E)$ is the flux in ions (or neutrals)/ $\mathrm{cm}^{2}$ sec. 
The fluxes $J_{i}(E)$ that produce a yearly erosion rate of $0.01 \mathrm{~cm} /$ year using the above equations together with experimental data or our estimates for $S_{i}(E)$ for $D, T$, He, and Arcat two characteristic energies are given in Table II. The maximum acceptable $(D, T)$ flux at $100 \mathrm{eV}$ is about $5 \times 10^{15}$ ions $/ \mathrm{cm}^{2}$. This energy was chosen as typical of the erosion rate from low energy particle bombardment and is in a region where the sputtering scales roughly linearly with energy. The existence of a plasma sheath near the walls that is $\sim 4 \mathrm{kT} e$ ( $\mathrm{T}_{\mathrm{e}}$ is the electron temperature) results in multi-charged ions bombarding the walls at higher energies and producing more damage. Table II shows that if $8 \%$ of the bombarding ions are $200 \mathrm{eV} \mathrm{He}{ }^{2+}$, the erosion rate doubles, and if $2 \%$ are argon, the erosion rate increases by a factor of two or more depending on the ionization states of the argon.

The erosion rate in the $1-10 \mathrm{keV}$ region is not expected to vary much with the bombarding energy (see Table I). The data for $\therefore$ on stainless steel ${ }^{12}$ and $H, D$, and he on silver (Figs. 7 and 8 ) both support this. If all of the plasma ions leaving the PRSG reactor were to uniformly hit the first wall once, the flux would be $1.5 \times 10^{15}$ ions $/ \mathrm{cm}^{2}-\mathrm{sec}$. (This is the number of exiting particles divided by the first wall area.)

These calculations suggest that the wall erosion rate from D, T, and He particles that escape from the plasma will be tolerable provided: (1) these escaping particles strike the wall no more than once before they are pumped. (The divertor should prevent most of them from striking the wall even once.), (2) there are not locally high fluxes such as at the divertor entrance or near 
the refueling entrance, and (3) the estimated sputtering yields are accurate. The higher sputtering coefficient for argon necessitates a correspondingly lower flux that bombards the first wall. As mentioned earlier $\sim 10 \mathrm{keV}$ argon and helium bombardment of the first wall occurs primarily by instabilities in confinement and not by charge exchange with neutrals.

Erosion by the sputtered wall particles (e.g., Fe and Ni), will be negligible as long as their bombarding energy is below $\sim 1 \mathrm{keV}$. The divertor and scrape-off region ${ }^{4}$ is designed to prevent bombardment of these ions at higher energies.

In concluding this section on erosion by sputtering we wish to re-emphasize the lack of sputtering data on the proposed first wall alloy, and the uncertainty of the particle fluxes and energies that will bombard the wall. The combination of these two unknowns prevents an accurate prediction of the first wall erosion rate due to sputtering at this time.

\section{BLISTERING AND ASSOCIATED PHENOMENA}

Blistering, pitting, flaking, and exfoliation of surfaces subjected to bombardment by $\mathrm{H}^{+}, \mathrm{D}^{+}$, and $\mathrm{He}^{+}$have been reported for both metals and insulators. $1,2,23-28$ The available data indicate that blistering is favored by a low gas solubility and a high number of radiation-produced lattice vacancies which promotes the coalescence of the injected gas and vacancies to form gas-filled bubbles. The region at which bubble growth initiates corresponds to the projected range or penetration depth for the bombarding ion $\left(10^{3} \AA\right.$ for $\sim 10 \mathrm{keV} \mathrm{H}$ or He). 
Many factors are expected to influence the growth, migration, and eventual rupture of these bubbles. These include temperature, implantation rate and depth, re-solution probability of precipitated gas, radiation damage, local stress, yield strength, and target microstructure including grain size, crystallite orientation, and precipitated solid phases such as carbides. Unexpectedly high surface temperatures may develop due to subsurface bubbles lowering the thermal conductivity and result in evaporation, enhanced bubble growth, or surface rupture at a lower dose. Presently, the theoretical models for formation, growth, and rupture of gas bubbles cannot predict the magnitude and nature of the surface damage thus produced and experimental data on blistering of iron- or nickel-alloys are scant. The short range $(50 \AA$ A $)$ and $h i g h$ sputtering coefficient for $10 \mathrm{keV}$ argon imply that it will not cause blistering. On the other hand, we expect blistering to occur from bombardment with $>10 \mathrm{keV} \mathrm{He}$ and do not know about bombardment with $\sim 10 \mathrm{keV} \mathrm{H,} \mathrm{D,} \mathrm{or} \mathrm{T.}$ Bauer and Thomas ${ }^{1}$ have found that $300 \mathrm{keV}$ He implanted in stainless steel in the temperature range $-50^{\circ} \mathrm{C}$ to $500^{\circ} \mathrm{C}$ produces

a large amount of surface flaking after a critical He dose of 10 18 atoms $/ \mathrm{cm}^{2}$ whereas at temperatures above $600^{\circ} \mathrm{C}$. it results in ruptured surface blisters after doses of $5 \times 10^{17}$ atoms $/ \mathrm{cm}^{2}$. Their helium/gion flux was $6 \times 10^{13}$ ions $/ \mathrm{cm}^{2}-\mathrm{sec}$. A similar dependence has sis $_{\text {in }}$ een reported by Erents and McCracken for molybdenum bombarded by $36 \mathrm{keV} \mathrm{He}{ }^{+}$ions; ${ }^{2}$ the temperature ranges differed but the critical dose was still $\sim 5 \times 10^{17} \mathrm{He}$ atoms $/ \mathrm{cm}^{2}$. 
We will roughly estimate the wall erosion from He blistering by assuming that (1). the injected He collects in bubbles at a distance beneath the surface determined by the penetration depth and (2) after a critical dose $\left(\sim 10^{18}\right.$ ions $\left./ \mathrm{cm}^{2}-\mathrm{sec}\right)$ the gas pressure becomes sufficient to result in the exfoliation of this retaining surface. The penetration depth or projected range for 6 - $60 \mathrm{kev} \mathrm{He}$ in $\mathrm{Fe}$ or $\mathrm{Ni}$ is given by

$$
R(\AA)=31 \mathrm{E}(\mathrm{keV})
$$

which we calculate using the theory of Shiott $^{29}$ for light ion ranges $R$ as a function of energy $E$. The yearly erosion rate, $B$, is

$$
\begin{aligned}
B(\mathrm{~cm}) & =\frac{\mathrm{R}(\stackrel{\circ}{\mathrm{A}})}{10^{8} \AA / \mathrm{cm}} \cdot \frac{\mathrm{J}\left(\text { ions } / \mathrm{cm}^{2}-\mathrm{sec}\right)}{10^{18} \text { ions } / \mathrm{cm}^{2}} \cdot 3.1 \times 10^{7} \mathrm{sec} / \text { year } \\
& =3.1 \times 10^{-19} \mathrm{R} . \mathrm{J}
\end{aligned}
$$

where $R$ is the range in $\AA, J$ is the flux in ions (or atoms) $/ \mathrm{cm}^{2}-s e c$. Substitution for $R$ in terms of $\mathrm{E}$ gives

$$
\mathrm{B}=9.6 \times 10^{-18} \cdot \mathrm{J} \cdot \mathrm{E} \mathrm{cm} / \text { year }
$$

Thus bombardment with $10^{14} \mathrm{He}$ ions $/ \mathrm{cm}^{2}-\mathrm{sec}$ at $50 \mathrm{keV}$ causes an estimated erosion of $0.05 \mathrm{~cm} /$ year or $10^{14} \mathrm{He}$ ions $/ \mathrm{cm}^{2}-\mathrm{sec}$ at $10 \mathrm{keV}$ causes an estimated erosion of $0.01 \mathrm{~cm} / \mathrm{year}$ due to blistering. The sputtering-associated erosion in either case is estimated to be $0.01 \mathrm{~cm} /$ year.

Hydrogen is known to permeate through metals and have a higher solubility than helium. This is the basis for predicting that blistering from hydrogen implantation will occur less often 
and require larger doses. This has been somewhat verified by the


blistering after a fluence of $\sim 10^{19}$ ions $/ \mathrm{cm}^{2}$ and that the surface damage is less severe than from $500 \mathrm{keV}$ He bombardment. However, blistering in niobium from implanted D was unexpected and indicate the important role that radiation damage and kinetic effects must play in bubble formation. A simple steady state diffusion model using the diffusion coefficient for $\mathrm{D}$ in undamaged $\mathrm{Nb}$ would predict a maximum implanted $D$ concentration of $\sim 10^{-2}$ appm, well within the solubility limits.

The fact that deuterium-bombarded $\mathrm{Nb}$ blisters suggests that deuterium-bombarded iron- and nickel-based alloys may also blister. However, experiments will be necessary to determine if blistering does occur and if significant wall erosion occurs by this mechanism. Also the simultaneous bombardment of $D, T$, and He could result in synergistic effects associated with changes in the bombarded surface region due to the presence of two injected gases. (The projected ranges for $10 \mathrm{keV} \mathrm{D,} 10 \mathrm{keV} \mathrm{T,}$ and $20 \mathrm{keV}$ He are essentially the same.)

\section{DISCUSSION}

Limited experimental data are available on pertinent sputtering yields and blistering of iron, nickel, and their alloys subjected to ion bombardment with $\mathrm{H}^{+}, \mathrm{D}^{+}, \mathrm{He}^{+}$or $\mathrm{Ar}^{+}$. The sputtering data were obtained before blistering from injected $H, D$, and He had been observed. The study of blistering and associated 
phenomena is in the stage of characterizing the dependence of the surface damage on a few parameters-fluence, temperature, target material; information is not yet available to forecast the cumulative wall damage and erosion from long term particle bombardment. The large threshold dose $\left(\tilde{>} 10^{17}\right.$ ions $\left./ \mathrm{cm}^{2}-\mathrm{sec}\right), \mathrm{microscopic}$ size ( $\left.10^{-6}-10^{-3} \mathrm{~cm}\right)$, and impulisive gas release with surface rupture typical of blistering make it difficult to ascertain whether possible erosion contribution from blistering were measured in some of the early. sputtering experiments.12,14,16,19 Considerations of the depth of bubble formation and associated fluence required for surface damage allows us to estimate that blistering and sputtering produce a comparable amount of wall erosion for $10 \mathrm{keV} \mathrm{He}{ }^{+}$bombardment and that the erosion from blistering becomes dominant at higher energies. Blistering from H and D bombardment of $\mathrm{Fe}, \mathrm{Ni}$, and their alloys has not been observed but could occur.

We estimate from existing sputtering data that bombardment of . the first wall with a relatively large flux $\left(5 \times 10^{14}\right.$ ions $\left./ \mathrm{cm}^{2}-\mathrm{sec}\right)$ of $10 \mathrm{keV}(\mathrm{D}, \mathrm{T})$ neutrals or ions will erode the first wall $0.01 \mathrm{~cm} /$ year, however, for a similar erosion rate the flux of $10 \mathrm{keV}$ argon must be down by two orders of magnitude and the flux of $10 \mathrm{keV}$. He down by one order of magnitude. The erosion rates are expected to remain essentially constant over the energy range 1 - $10 \mathrm{keV}$ and decrease approximately Iinearly with energy below $1 \mathrm{keV}$. The plasma sheath potential $(\sim \mathrm{kT} \mathrm{T})$ can result in 
significant acceleration of ions prior to wall bombardment and add significantly to the erosion rate from low temperature ( $25 \mathrm{eV}$ ) plasmas, especially when multi-charged He- and Ar-ions are present.

No experimental data exist on nickel and iron alloys under prolonged and/or simultaneous bombardment with $\mathrm{H}-, \mathrm{D}-$, He-, and Ar-ions or neutrals in the energy range $5 \mathrm{eV}$ to $50 \mathrm{keV}$. Such experiments are needed since the erosion from combined bombardment is unlikely to be the sum of separate erosion rates-especially when blistering occurs.

Experimental programs are needed to study the bombardment of proposed first wall alloys at expected operating temperatures with $\mathrm{H}^{+}, \mathrm{D}^{+}$, and $\mathrm{He}^{+}$at energies from $\sim 50 \mathrm{keV}$ down. It is hoped that in our presentation of experimental data on $\mathrm{Fe}, \mathrm{Ni}$, and $\mathrm{Cr}$ and subsequent use of it to estimate erosion rates of ferrous- or nickel-alloys that the scarcity of data and uncertainty in our estimated erosion rates were noted. In addition to measuring gross erosion rates, such a program should aim at characterizing and understanding the factors that determine both (1) the migration, hold up and re-emission of the injected $H, D$, and He atoms and (2) the energy and identity of material eroded from the surface: This is important because of possible plasma contamination and interest in anticipating the hold up or migration through the first wall of tritium. 
Experimental Plasma Devices

The influx of cold neutral atoms (metal and $\mathrm{H}$ ) from the limiters and vacuum walls are affecting quasi-steady-state plasma discharges such as the ATC and ST Tokamaks. The prospect of higher plasma temperatures resulting from a lowering of the radiative energy losses through Bremsstrahlung and line radiation make it desirable to minimize high $\mathrm{Z}$ impurities in the plasma either by using a magnetic divertor or "low-contaminating" materials for the limiter and vacuum walls. The concentration of metal impurities entering the plasma depends on the energy, charge, and spatial distribution of metal particles ejected from the limiter and divertor under the existing set of bombardment conditions. Such detailed information on sputtering (or possibly blistering or evaporation) is not generally available. The sputtering. yields for $300 \mathrm{eV} \mathrm{He}$ and $7.5 \mathrm{keV} \mathrm{\textrm {H } _ { 2 }}{ }^{+}$, for a variety of metals, as plotted in Figs. 5 and 6 , provide a somewhat reliable gauge for. judging the relative contaminating tendency of materials for interior use in plasma devices.

The sputtering yields for bombardment with light particles, such as $\mathrm{H}$ or $\mathrm{He}$, decrease with increasing atomic weight of the target material; the sputtering yields for any bombarding particle on transition metal targets increase with the filling of the d-electron shell reaching maxima at $\mathrm{Cu}$, $\mathrm{Ag}$, and $\mathrm{Au}$. A comparison of sputtering yields from stainless steel and gold (used in ORMAK is of interest but inconclusive since for $300 \mathrm{eV} \mathrm{He}{ }^{+}$bombardment apparently the increase in mass dominates the filling of the 
d-electron shell since the yield for $A u$ is one-half the yield for Fe. On the other hand, for bombardment with $7.5 \mathrm{keV} \mathrm{Hg}$ $\left(3.7 \mathrm{keV} \mathrm{\textrm {H } ^ { + }}\right.$ ) the reverse is true with the yield for $\mathrm{Au}$ being twice the yield for $\mathrm{Fe}$. rive advantage of gold-plating the walls is questionable for future higher-energy plasma devices, especially for $\mathrm{H}$ plasmas.

Limiters, which receive the heaviest particle bombardment, are usually made from Mo or $W$, both of which are heavy early transition metals and have low sputtering yields. These metals might make interesting liners for plasma devices as divertors since they are low-sputtering metals and do not form stable hydrides.

The use of the earliest transition metals for interiors in plasma devices is certainly suggested by their low-sputtering yields in Figs. 5 and 6 . However, $\mathrm{Ti}, \mathrm{V}, \mathrm{Zv}, \mathrm{Nb}$, and $\mathrm{Ta}$ form stable metal hydrides at low temperatures which may result in a deterioration of mechanical properties. Numerous papers and books on the metal hydrides are available $30-32$; however, the characteristics of metal hydrogen reactions at low temperatures ( $<300^{\circ}$ C) are poorly described and very sensitive to small details such as impurity content.

In conclusion we would like to point out that experimental programs characterizing the interaction of energetic $\mathrm{H}$ and $\mathrm{He}$ particles with metal surfaces are pertinent both to reactor technology and to current experimental plasma devices. 


\section{ACKNOWLEDGMENTS}

The author wishes to express her appreciation to R. C. Axtmann for helpful discussions during the preparation of this paper. Thanks are also due to P. Bonanos, S. Cohen, R. G. Mills, and F. H. Tenney for reading the manuscript. Acknowledgment is due G. Lewin; S. Gralnick, and F. H.: Tenney for explaining the temperature profile and particle transport expected in the Princeton Reactor Studies Group design reactor.

This work was supported in part by U. S. Atomic Energy Commission Contracts AT(11-1)-3073, AT(11-1)-3028, and Edison Electric Institute Project RPI13. 
REFERENCES

${ }^{1}$ W: Bauer and G. J. Thomas, "Helium re-emission and surface deformation in 316 stainless steel during $-170^{\circ} \mathrm{C}$ to $700^{\circ} \mathrm{C}$ implatations," J. Nucl. Mat. (to be published).

${ }^{2}$ G. M. McCracken and S. K. Erents, "Blistering of molybdenum under helium ion bombardment." Paper presented at the International Conference on Ion-Surface Interaction, Sputtering \& Related Phenomena, Garching, Germany, Sept. 25-28, 1972.

${ }^{3}$ S. Gralnick (private communication).

${ }^{4}$ F. Tenney and G. Lewin (private communication).

${ }^{5} \mathrm{G}$. Carter and J. Colligon, Ion Bombardment of Solids (American Elsevier Publishing Co., New York, 1968).

${ }^{6}$. Behrisch, "Festkorperzerstaubung durch ionenbeschuss." Ergeb. Exakt. Naturw. 35, 295 (1964); "First-wall erosion in fusion reactors," Nucl. Fusion 12, 695 (1972).

7M. Kaminsky, Atomic and Ionic Impact Phenomena on Metal Surfaces (Springer-Verlag, New York, 196.5).

${ }^{8}$ R. S. Nelson, The Observation of Atomic Collisions in Crystalline Solids (North-Holland, Amsterdam, 1968).

${ }^{9}$ M. W. Thompson, Defects and Radiation Damage in Metals (Cambridge, 1969).

${ }^{10} \mathrm{P}$. Sigmund, "Theory of sputtering. I. Sputtering yield of amorphous and polycrystalline targets," Phys. Rev. 184, 383 (1969) . 
${ }^{11}$ U. A. Arifov, Interaction of Atomic Particles with a solid Surface (Consultants Bureáu, New York, 1969).

12 M. I. Guseva, "Sputtering of stainless steel and tantalum by deuterium and krypton ions with energies of 5-30 kev,". Radioengineering and Electronic Physics 2, 1563 (1962):

${ }^{13} \mathrm{G} \cdot \mathrm{K}$. Wehner, "Sputtering yield data in the $100-600 \mathrm{eV}$ energy range," General Mills Report 2309, July 1962.

${ }^{14} \mathrm{D}$. Rosenberg and G. K. Wehner, "Sputtering yields for low energy $\mathrm{He}^{+}-, \mathrm{Kr}^{+}-$, and $\mathrm{Xe}^{+}$- ion bombardment," J. Appl. Phys. 33, 1842 (1962).

${ }^{15} \mathrm{~N}$. Laegreid and. G. K. Wehner, "Sputtering yields of metals for $\mathrm{Ar}^{+}$and $\mathrm{Ne}^{+}$ions with energies from 50 to $600 \mathrm{eV}, " \mathrm{~J}$. Appl. Phys. 32,365 (1961).

${ }^{16}$ C. E. Kenknight and G. K. Wehner, "Sputtering of metals by hydrogen ions," J. Appl. Phys. 35, 322 (1964).

${ }^{17}$ C. H. Weijsenfeld, A. Hoogendoorn, and M. Koedam, "Sputtering of polycrystalline metals by inert gas ions of low energy (100-1000 ev)," Physica 27, 763 (1961).

${ }^{18}$ F. Gronlund and W. J. Moore, "Sputtering of silver by light ions with energies from 2 to $12 \mathrm{keV}, " \mathrm{~J}$. Chem. Phys. 32 , 1540 (1960). ${ }^{19}$ F. Fairbrother, Jr. and J. S. Foster, Jr., "Sputtering of stainless steel by protons in the 30-80 keV range," Vacuum $\underline{4}$, 112 (1954) 
200. Almen and G. Bruce, "Sputtering experiments in the high energy region," Nucl. Instr. \& Methods 1.1, 279 (1961) .

${ }^{21}$ L. I. Maissel and R. Glang, editors, Handbook of Thin Film: Technology (McGraw-Hill, New York, ), pp. 4-40.

22 E. S. Borovik, N. P. Katrich,, and G. T. Nikolaev, "Interaction of fast $\mathrm{H}_{1}^{+}$ions with metal surfaces in very high vacuum," Soviet Atomic Energy 21, 1019 (1966).

${ }^{23}$ R. S. Blewer: and J. K. Maurin, "Dimensional expansion and surface microstructure in helium implanted erbium and erbiumhydride films," J. Nuç . Mat. 4.4, 260 (197.2) :

${ }^{24}$ R. S. Barnes and D. J. Mazey, "The migration and coalescence of inert gas bubbles in metals," Proc.. Roy. Soc. (London) 275, 47 (1963)

25 a. W. Bauer and G. J. Thomas, "Helium release and electron-microscopy of helium-implanted palladium," J.. Nucl. Mat:. 42, 96 (1972).

b. W. Bauer and D. Morse, "Helium implantation and: re-emission from niobium at elevated temperatures." J. Nucl. Mat. 44, 318 (1972).

c. G. J. Thomas, W. Bauer, and J. B. Holt, "Helium migration in palladium. II. Scanning electron microscopy examination of high concentration samples," Radiation Effects 8, 27 (1971).

d. J. B. Holt, W. Bauer, and S. J. Thomas, "Helium migration in palladium. I. Concentration dependence of helium release," Radiation Effects 7 , 269 (1971). 
26

a. M. Kaminsky, "Mass spectrometric studies of the species of particles leaving a monocrystalline target in a charged or uncharged state under high energy ion bombardment," Advan: Mass spectrometry $\underline{3}, 69(1964)$.

b. M. Kaminsky and S. K. Das, "Blistering of polycrystalIine and monocrystalline niobium." "Paper presented at the International Conference on Ion Surface Interaction-Sputtering, Garching, Germany, Sept. 25-28, 1972 .

C. M. Kaminsky and S. K. Das, "Effect of channeling and irradiation temperature on the morphology of blisters in niobium," Appl. Phys. Lett. 21, 443 (1972).

d. S. K. Das and M. Kaminsky, "Radiation blistering of polycrystalline niobium by helium-ion implantation," $J$. Appl. Phys. 44,25 (1973)。

27 a. L. H. Milacek, R. D. Daniels, and J. A. Cooley, "Proton-radiation-induced blistering of aluminum," J. Appl: Phys. 39. 2803 (1968).

b. L. H. Milacek and R. D. Daniels, "Orientation dependence of pitting and blistering in proton-irradiated aluminum crystals," J. Appl. Phys. 39, 5714 (1968).

28 a. W. Primak, "Radiation-induced cavities and exfoliation," J. Appl. Phys. 34, 3630 (1963).

b. W. Primak, Y, Dayal, and E. Edwards, "Ion bombardment of Silicon," J. Appl. Phys. 34, 827 (1963) .

c. W. Primak and J. Luthra, "Radiation blistering: interferometric and microscopic observations of oxides, silicon, and metals," J. Appl. Phys. 37, 2287 (1966). 
${ }^{29}$ H. E. Shiott, "Approximation and interpolation rules for ranges and range stragglings," Radiation Effects 3, 107 (1970).

${ }^{30}$ W. M. Mueller, J. P. Blackledge, and G. C. Libowitz, Metal Hydrides (Academic Press, New York, 1968).

$31_{\mathrm{H}}$. J. Goldschmidt, Intersitial Alloys (Butterworths, L̇ondon, 1967).

${ }^{32}$ L. C. Beavis, "Characteristics of some binary transition metal hydrides," J. of Less-Common Metals 19, 315 (1969). 
TABLE I. Sputtering yield data on Fe, $\mathrm{Cr}$, Ni

\section{Target Fe}

$$
\text { Yield } \mathbf{d}^{+}
$$

$7.5 \mathrm{keV} \mathrm{H}_{2}^{+}$

$0.024^{a}$

$8.0 \mathrm{keV} \mathrm{H}_{2}^{+}$

$0.017^{\mathrm{a}}$

$7.5 \mathrm{keV} \cdot \mathrm{H}_{3}^{+}$

$0.030^{a}$

$8.0 \mathrm{keV} \mathrm{H}_{3}^{+}$

$0.022^{a}$

6-30 kev D

$0.05-0.02^{b *}$

$35 \mathrm{keV} \mathrm{H}^{+}$.

$0.009^{c^{*}}$

$36 \mathrm{keV}\left(\mathrm{H}^{+}, \mathrm{H}_{2}^{+}\right)$

$0.009^{d^{*}}$

$51 \mathrm{keV}\left(\mathrm{H}^{+}, \mathrm{H}_{2}^{+}\right)$

$0.016^{d^{*}}$

$75 \cdot \mathrm{keV} .\left(\mathrm{H}^{+}, \mathrm{H}_{2}^{+}\right)$

$0.009^{d *}$

$100 \mathrm{eV} \mathrm{He}^{+}$

$0.030^{\mathrm{e}}$

$600 \mathrm{eV} \mathrm{He}{ }^{+}$

$0.170^{e}$

$100 \mathrm{eV} \mathrm{Ar}{ }^{+}$

$0.20^{f} \quad 0.1^{g}$

$600 \mathrm{eV}$ Art.

$1.26^{\mathrm{f}} \cdot 0.9^{\mathrm{g}}$

$1000 \mathrm{eV}^{\text {Ar }}{ }^{+}$

$1.4^{h \cdot g}$

2000 eV Ar ${ }^{+}$

$2.0^{\mathrm{h} *}$

$5000 \mathrm{eV} \mathrm{Ar}^{+}$

$2.5^{h *}$

$1.1 \mathrm{keV} \mathrm{Fe}^{+}$

$1.1^{i}$

$45 \mathrm{keV} \mathrm{Fe}^{+}$

$2.9^{i}$

Target $\mathrm{Ni}$.
$7.2 \mathrm{keV} \mathrm{H}{ }_{2}^{+}$
$0.037^{a}$
$7.5 \mathrm{keV} \mathrm{H}_{2}^{+}$
$0.035^{a}$
$7.2 \mathrm{keV} \mathrm{H}_{3}^{+}$
$0.058^{a}$
$7.5 \mathrm{keV} \mathrm{H}_{3}^{+}$
$0.058^{a}$ 
TABLE I (Continued)

Target Ni (Cont'd)

$\begin{array}{ll}100 \mathrm{eV} \mathrm{He}^{+} & 0.028^{\mathrm{e}} \\ 600 \mathrm{eV} \mathrm{He}^{+} & 1.18^{\mathrm{e}} \\ 100 \mathrm{eV} \mathrm{Ar}^{+} & 0.28^{\mathrm{f}} 0.25^{\mathrm{g}} \\ 600 \mathrm{eV} \mathrm{Ar}^{+} & 1.52^{\mathrm{f}} 1.5^{\mathrm{g}} \\ 1000 \mathrm{eV} \mathrm{Ar}^{+} & 2.1^{\mathrm{g}, \mathrm{h}} \\ 1.0 \mathrm{keV} \mathrm{Ni}^{+} & 1.0^{\mathrm{i}} \\ 45 \mathrm{keV} \mathrm{Ni}^{+} & 3.8^{\mathrm{i}}\end{array}$

\section{Target $\mathrm{Cr}$}

$\begin{array}{ll}100 \mathrm{eV} \mathrm{He}^{+} & 0.030^{\mathrm{e}} \\ 600 \mathrm{eV} \mathrm{He} & 0.20^{\mathrm{e}} \\ 100 \mathrm{eV} \mathrm{Ar}^{+} & 0.30^{\mathrm{f}} \\ 600 \mathrm{eV} \mathrm{Ar}^{+} & 1.30^{\mathrm{f}} \\ 45 \mathrm{keV} \mathrm{Cr} & 1.0^{\mathrm{i}}\end{array}$

+ The yield is per bombarding particle where $\mathrm{H}_{2}^{+}$is counted as one bombarding particle

* stainless steel

a ref. 16

b ref. 12

c ref. 22

d ref. 19

e refs. 13,14

f refs. 13,15

g ref. 17

$h$ ref. 21

i ref. 20 
TABLE II

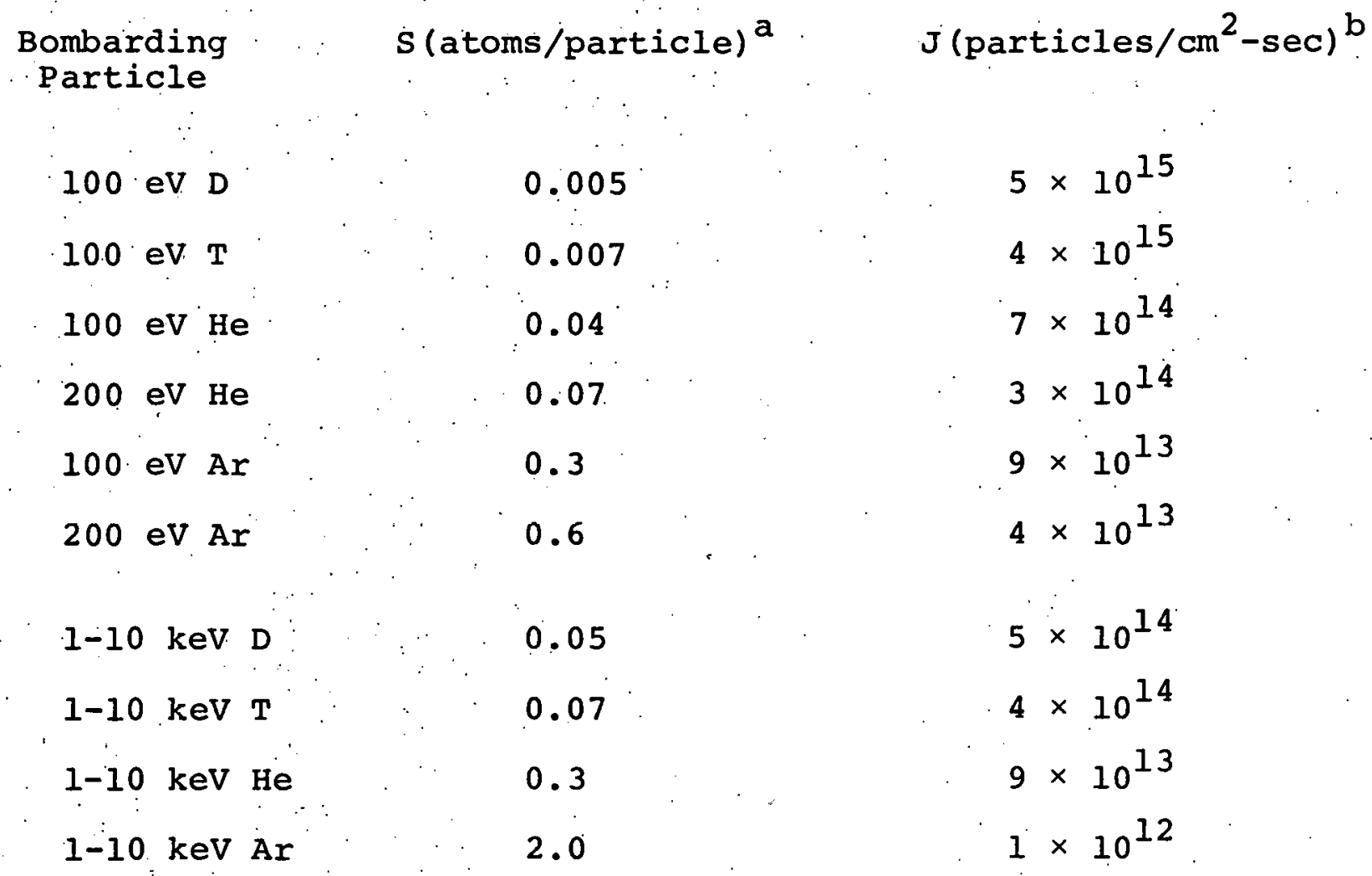

a Estimated values. . See sputtering section

b Flux that is expected to produce an erosion rate of $0.01 \mathrm{~cm} /$ year. 


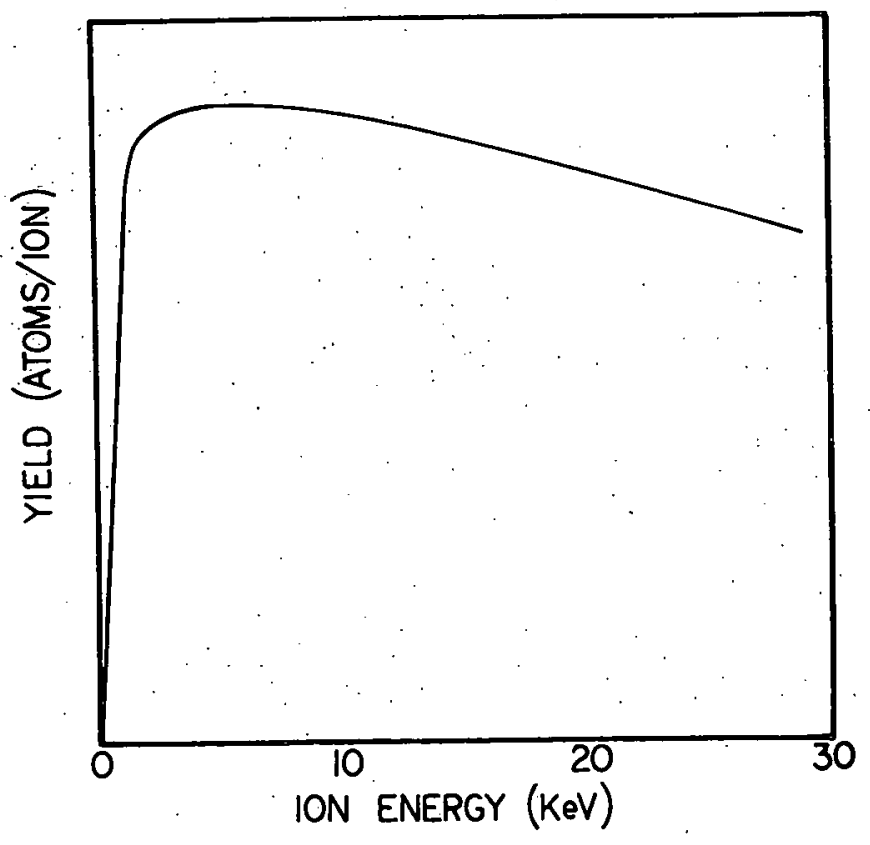

734223

Fig. 1. A representive sputtering curve to demonstrate the energy dependence of the yield.

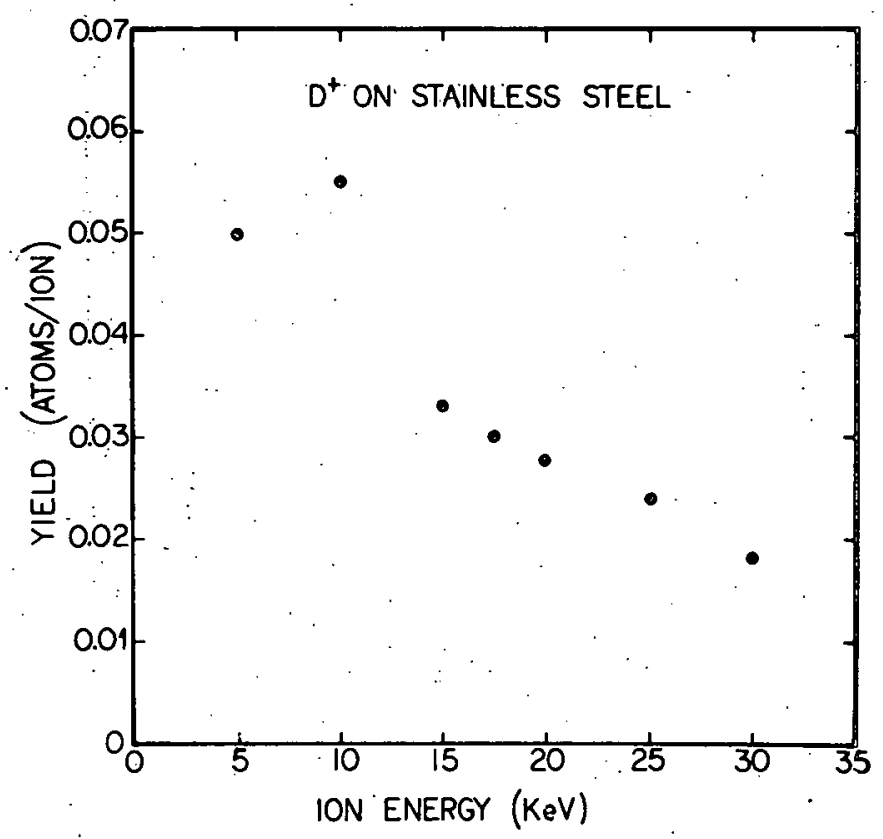

734222

Fig. 2. The sputtering yield for $\mathrm{D}^{+}$bombardment of stainless steel as a function of ion energy. Data from ref. [12]. 
Fig, 3. sputtering yield (uncorrected for secondary electrons) of lcw energy $\mathrm{He}^{+}$ on Cr, Ni, and $\mathrm{Fe}$. Data from ref. [13].

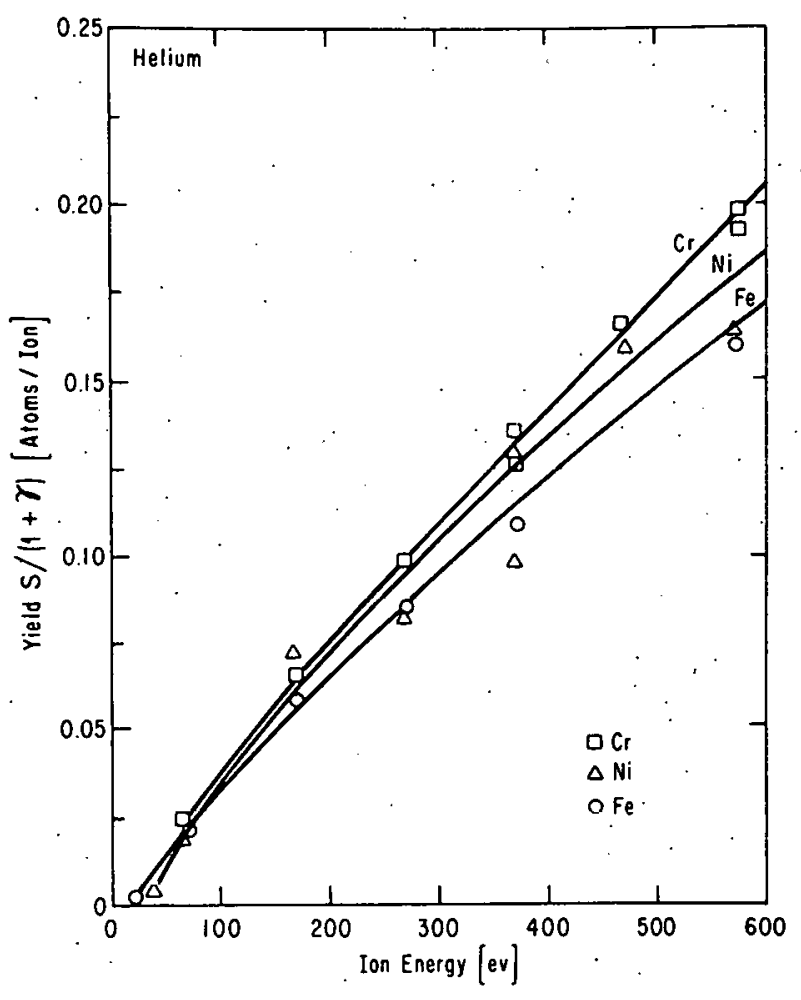

734219

Fig. 4. Sputtering yield (uncorrected for secondary electrons) of lcw energy $\mathrm{Ar}^{+}$ on $\mathrm{Cr}, \mathrm{Ni}$, and $\mathrm{Fe}$. Data from ref. [13].

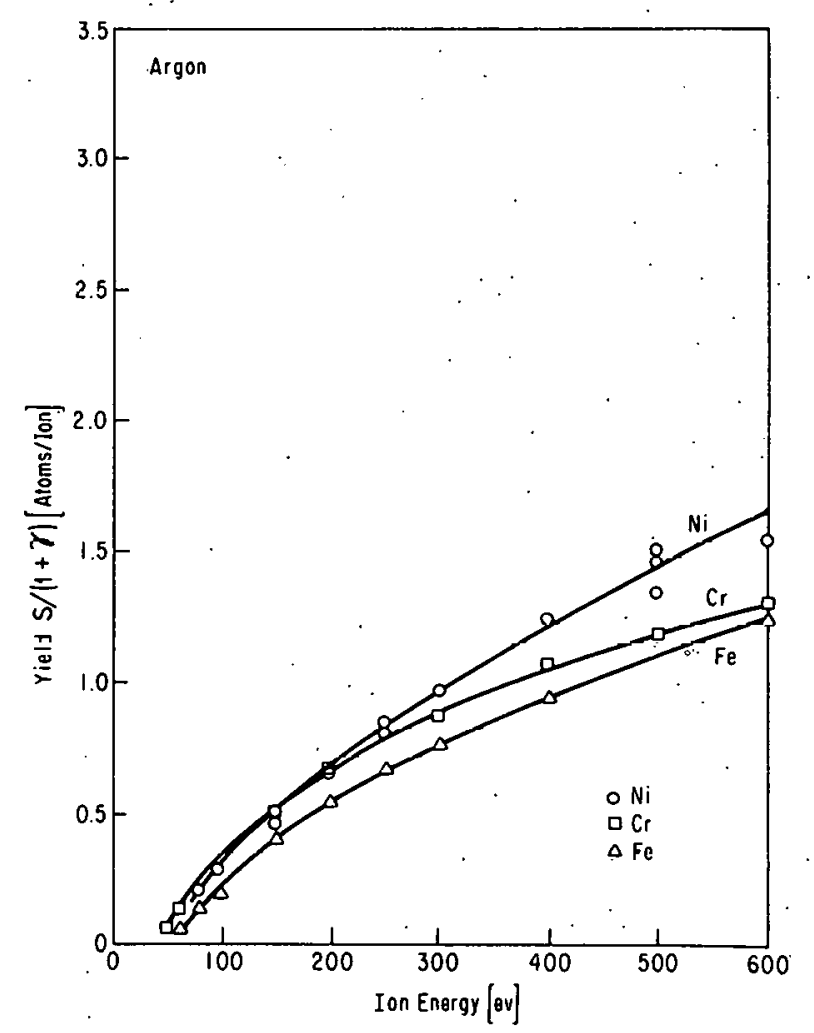




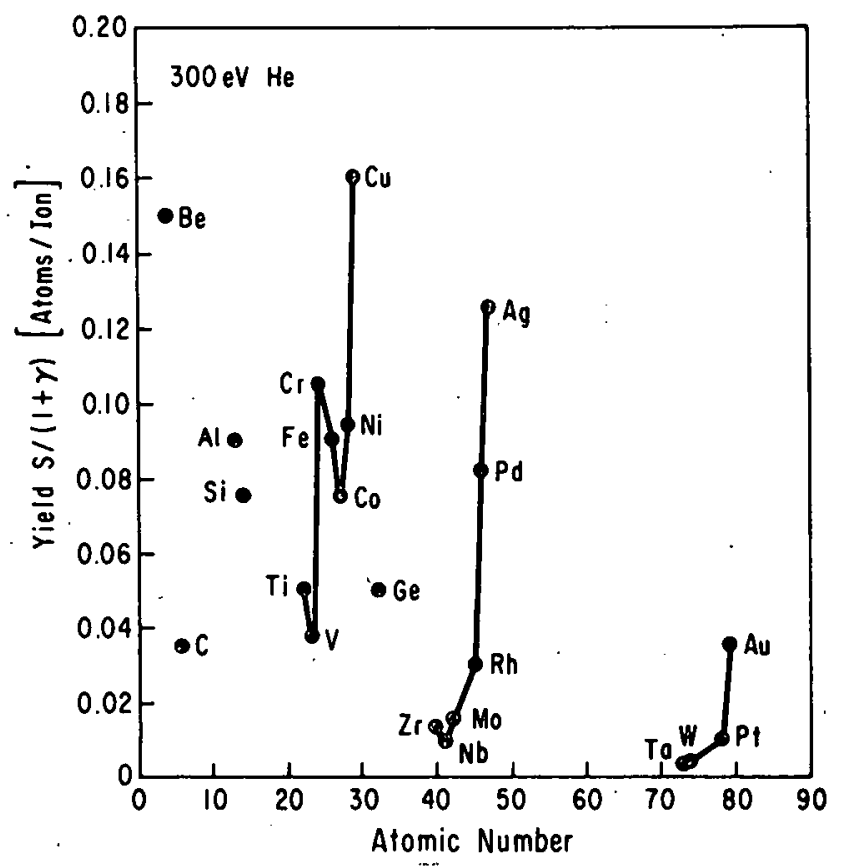

734216

Fig. 5. The sputtering yield for $300 \mathrm{eV} \mathrm{He}{ }^{+}$ bombardment as a function. of the target's atomic number. The divisor $(1+\gamma)$ indicates that the ion current was uncorrected for secondary electron yield $\gamma$. Data from ref. [14].

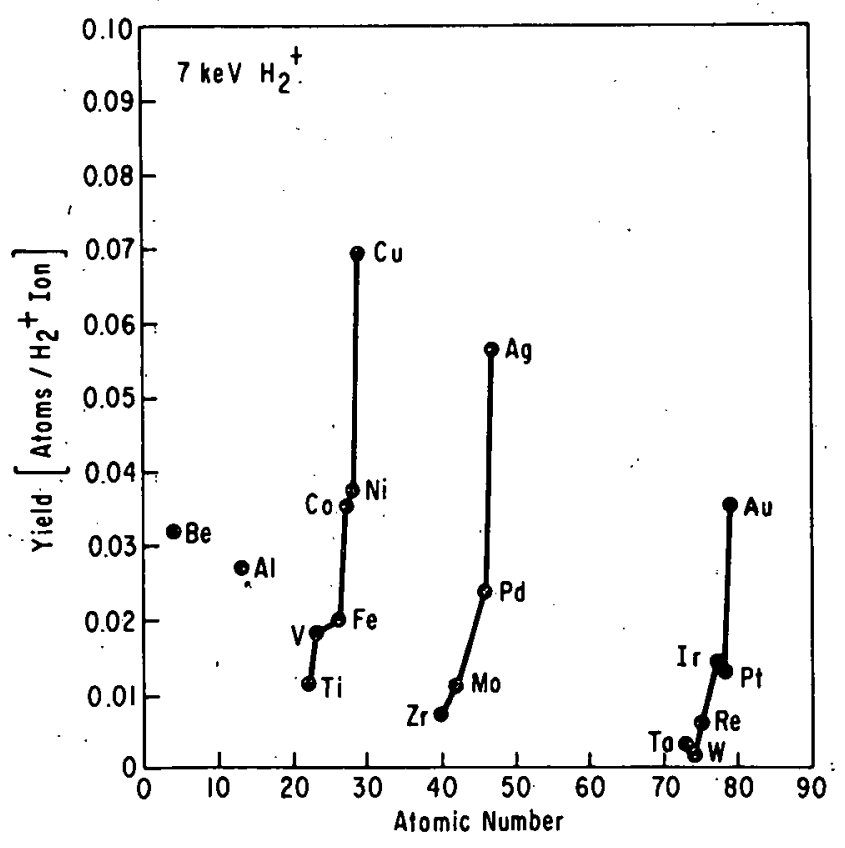

734217

Fig. 6. Sputtering yield for $7 \mathrm{keV} \mathrm{H}_{2}^{+}$ bombardment as a function of the target's atomic number. Data from ref. [16]. 




734221

Fig. 7. Sputtering yield of $\mathrm{He}^{+}, \mathrm{D}^{+}$, and $\mathrm{H}^{+}$ on silver as a function of energy.

Figure from ref. [18].

734220

Fig. 8. Sputtering yield of $\mathrm{D}_{3}^{+}, \mathrm{D}_{2}^{+}, \mathrm{H}_{3}^{+}$, and $\mathrm{H}_{2}^{+}$on silver as a function of energy.

Figure from ref. [18].

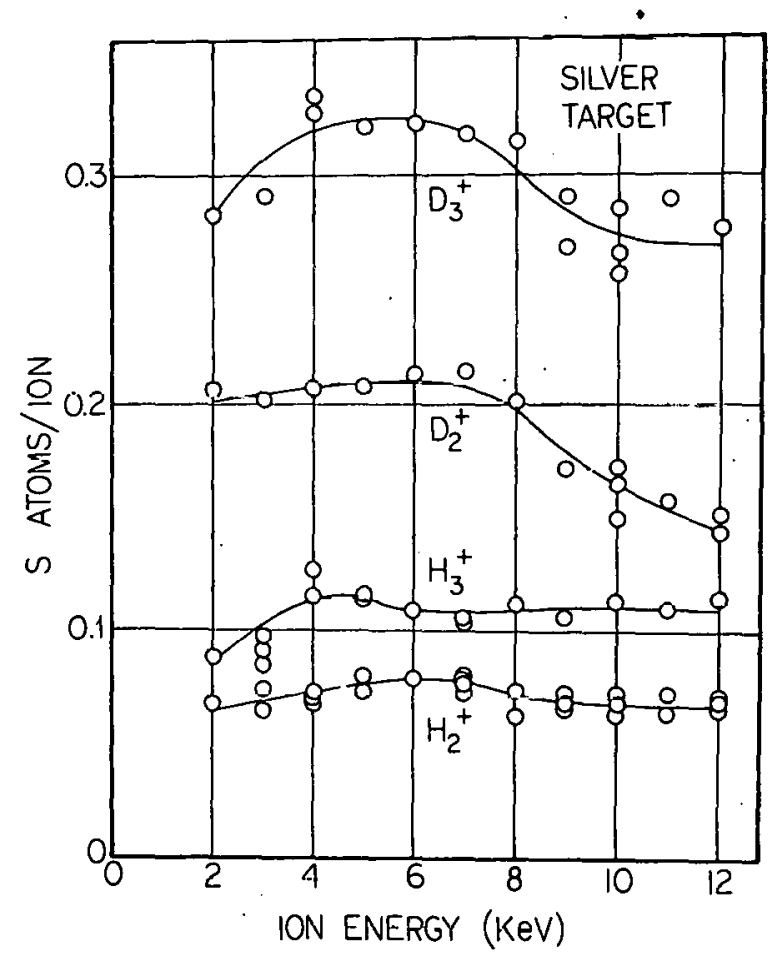


LEGAL NOTI C E

This report was prepared as an account of Government sponsored work. Neither the United States, nor the Commission, nor any person acting on behalf of the Commission:

A. Makes any warranty or representation, express or implied, with respect to the accuracy, completeness, or usefulness of the information contained in this report, or that the use of any information, apparatus, method, or process disclosed in this report may not infringe privately owned rights; or

B. Assumes any liabilities with respect to the use of, or for damages resulting from the use of any information, apparatus, method, or process disclosed in this report.

As used in the above, "person acting on behalf of the Commission" includes any employee or contractor of the Commission to the extent that such employee or contractor prepares, handles or distributes, or provides access to, any information pursuant to his employment or contract with the Commission. 